\title{
ENDEUDAMIENTO EN TUNGURAHUA
}

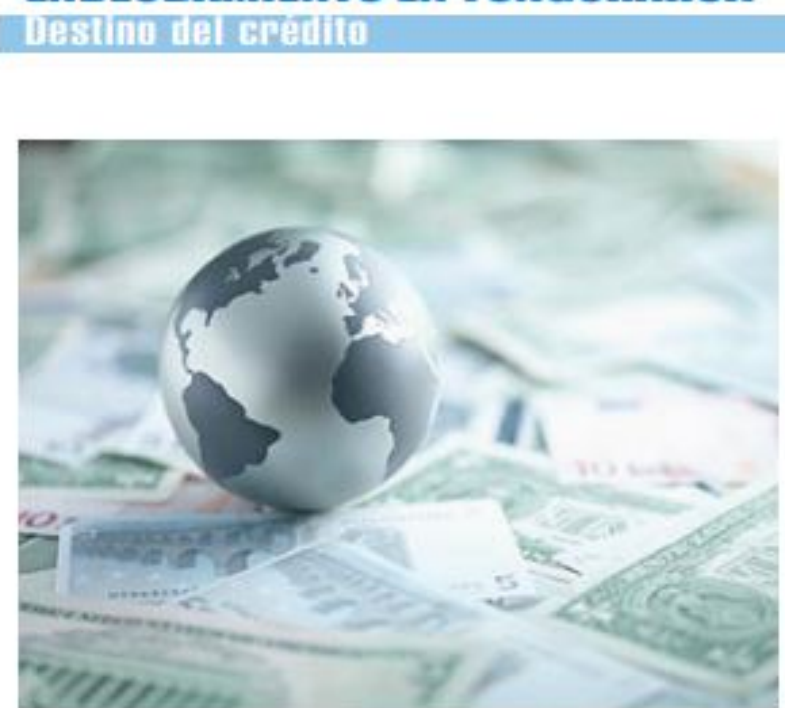

La alternativa para aquellas personas que en un momento determinado no cuentan con dinero suficiente para adquirir un bien o un servicio de contado, aprovechando oportunidades y ofertas en temporadas especiales o por casos fortuitos o emergentes, constituye el crédito; este es el sistema de pago por medio del cual se adquiere un bien o un servicio con el compromiso de la cancelación a futuro.

De acuerdo con los datos presentados en la sexta ronda de la encuesta sobre condiciones de vida (ECV) 2013-2014 realizado por el INEC, (Figura 1) se puede identificar claramente que el mayor endeudamiento de los ecuatorianos es por compra de Electrodomésticos, representando el $42,58 \%$ del crédito o endeudamiento a nivel nacional, seguido de la compra de vehículos con el $32,94 \%$. Se refleja que los porcentajes de endeudamiento en medicina y educación, tanto a nivel urbano como rural son prácticamente nulos, esto debido a que tanto la Salud como la Educación en su mayoria son gratuitas. Muchos acuden a los Hospitales del IESS, Centros de Salud, Hospitales Públicos, y las diferentes instituciones de educación fiscal ubicados a nivel nacional; otro factor a tomar en cuenta es que el Gobierno a través del Ministerio de Educación otorga becas para quienes deseen capacitarse dentro o fuera del pais, a las que fácilmente se puede acceder.

En la Tabla 1 se puede distinguir que a nivel nacional, el endeudamiento en la zona urbana es del $70 \%$ del total nacional; el endeudamiento por adquisición de electrodomésticos y vehículos suman un $52 \%$ en la zona urbana y un $24 \%$ en la zona rural. Adicionalmente, se puede visualizar que la zona rural no registra ningún tipo de crédito por compra de medicina durante el período analizado.
Figura 1

Compras a crédito - Nacional / 2013 - 2014

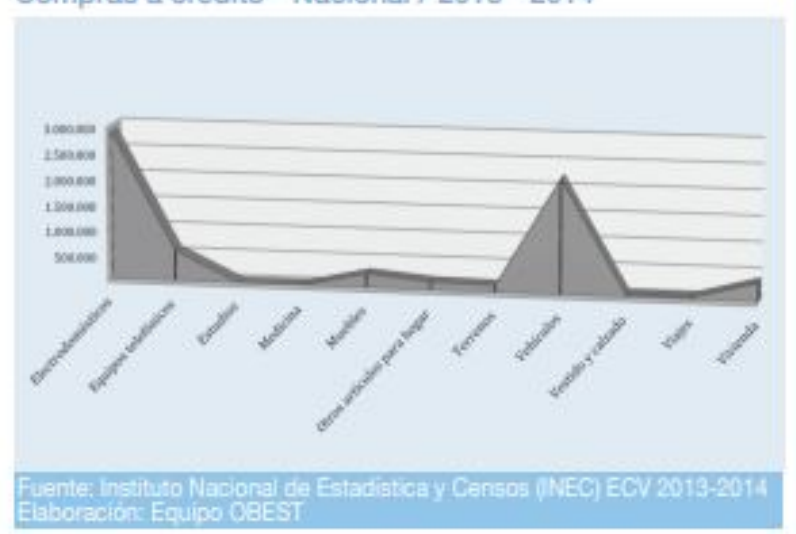

Tabla 1

Monto de compra a crédito / 2013 - 2014

\begin{tabular}{|c|c|c|c|}
\hline Bia cumprado & Rural & Trbano & Taral \\
\hline Eectrodomistors & 1032045 & $1815 \times 2$ & 2873.62 \\
\hline Equipos teleronticos & 171.812 & 424657 & $596+49$ \\
\hline Estudios & 48 & 7064 & 7.472 \\
\hline Medcing & & 6.819 & 68519 \\
\hline Muchles & 100827 & 172900 & 275.747 \\
\hline Otros articulos para bogur & 50.057 & $1119+9$ & 162005 \\
\hline Tenans & 13500 & 127.200 & 140.700 \\
\hline $\begin{array}{l}\text { Veticulhs } \\
\text { S }\end{array}$ & 568054 & 165400 & $22 m 2.545$ \\
\hline Vestido y calnado & 7215 & 43.296 & 50.511 \\
\hline Viajs & 132000 & 31.58 & 4.658 \\
\hline Viviende & 6523 & $302: 300$ & 367.573 \\
\hline Total & 2.04 .32 & 4.723 .75 & 6.748 .106 \\
\hline
\end{tabular}

En el 2014, Tungurahua registra un endeudamiento total de USD \$ 177.627, de los cuales el 56\% corresponde a la zona rural y el $44 \%$ a la urbana; esto, contrario a los porcentajes presentados a nivel nacional donde la zona urbana tuvo mayor endeudamiento.

Los datos más representativos corresponden a compras a crédito de electrodomésticos y vehículos; siendo el primero, más alto en la zona rural con $35 \%$ (USDS 61.924) y $20 \%$ en la zona urbana (USDS 35.919) con relación al total de la Provincia. La compra a crédito de vehículos es más alto en la zona urbana, representa un 15\% (USD\$26.200) y un $9 \%$ (USD\$ 16.300) en la zona rural. 
Figura 2

Endeudamiento por zona -Tungurahua 2013-2014

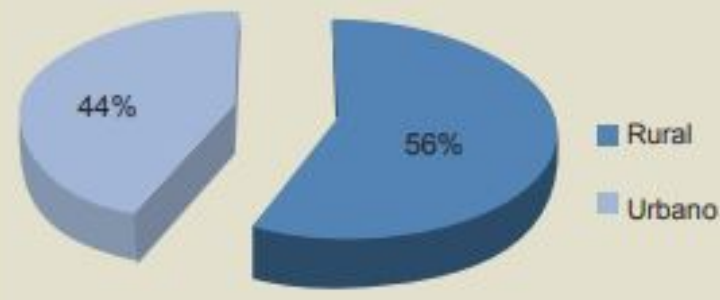

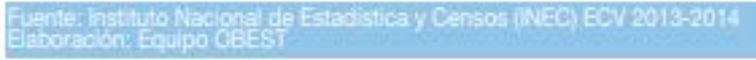

En relación al gasto por zona, los electrodomésticos tienen un $62 \%$ de endeudamiento en la zona rural y un $46 \%$ en la zona urbana; y los vehiculos $16 \%$ y $34 \%$ zona rural y zona urbana respectivamente.

Figura 3

Endeudamiento Rural - Tungurahua 2013 - 2014

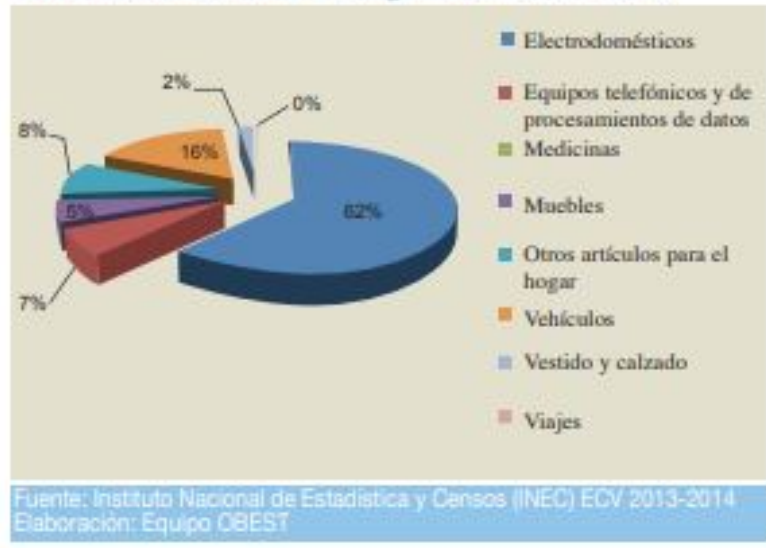

Figura 4

Endeudamiento Urbano - Tungurahua 2013 - 2014

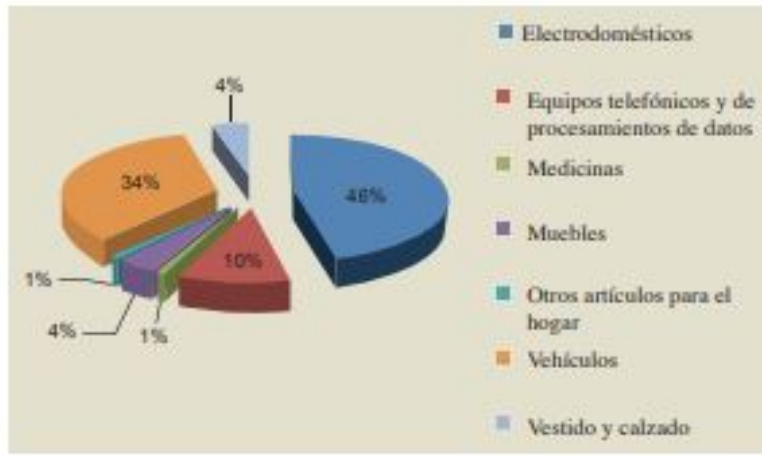

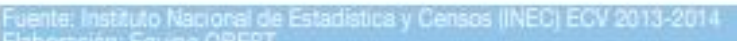

La tabla 2 indica la diferencia que existiria si al momento de realizar una compra, ésta se cancelaría al contado. Por ejemplo, en electrodomésticos y vehículos que son los artículos más representativos dentro del endeudamiento de la población, alcanzarian hasta un $24 \%$ y un $14 \%$ de ahorro estimado respectivamente; esto, debido a las tasas de interés que los locales comerciales o concesionarias agregan en una venta a crédito y que por lo general no se toma en cuenta al momento de realizar la misma. Los equipo telefónicos y procesamiento de datos, aunque sus valores solo representan un $8 \%$ del endeudamiento en la provincia, su ahorro estimado (USD \$ 3.872 ), es del $26 \%$ frente a la compra a crédito.

Se debe analizar además que las compras en articulos del hogar como electrodomésticos, muebles y otros, suman un $57 \%$ del ahorro estimado frente a la compra a crédito, resultando representativo para el bolsillo de los tungurahuenses.

Tabla 2

Compra a crédito vs compra de contado Tungurahua 2013 - 2014

\begin{tabular}{|c|c|c|c|c|}
\hline Biae caspode & \begin{tabular}{|c|}
$\begin{array}{c}\text { Campras } \\
\text { cotilate }\end{array}$ \\
\end{tabular} & 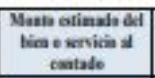 & $\begin{array}{l}\text { Alumers } \\
\text { stimsh }\end{array}$ & S Asers \\
\hline Elemedrabion & 978300 & 7425200 & 13 Mign & $14 \mathrm{~s}$ \\
\hline 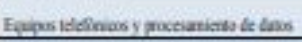 & Lassosos & $109 \times 50$ & 387200 & 265 \\
\hline Mahians & 5800 & $5 \mathrm{sinem}$ & & $n$ \\
\hline Matis & 300000 & 623000 & 1.8000 & $22 \mathrm{~s}$ \\
\hline 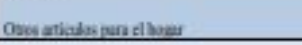 & 345200 & 799223 & 892 & 1115 \\
\hline Velioules & 4250000 & 3636000 & 610000 & 14: \\
\hline Vissiso veluabo & 518480 & 396500 & 118980 & 3 \\
\hline Vules & 200,00 & 20000 & & $\approx$ \\
\hline Iosi gratral & m.6me & 140.155 .20 & 37.A71:39 & \\
\hline
\end{tabular}

La flexibilidad en la concesión de créditos de consumo, las diversas promociones existentes y facilidades de pago en la adquisición de productos, facilita la compra de bienes y servicios y se convierte en una gran tentación difícil de ser rechazada por los consumidores, sin embargo, se debe tener en cuenta que se comprometen ingresos futuros y se debe prever posibles emergencias adicionales que no desfinancien la economia del hogar. Es necesario entonces planificar tanto el gasto como los ingresos, equilibrando el presupuesto para que los esfuerzos que se realicen en el pago no generen problemas económicos futuros.

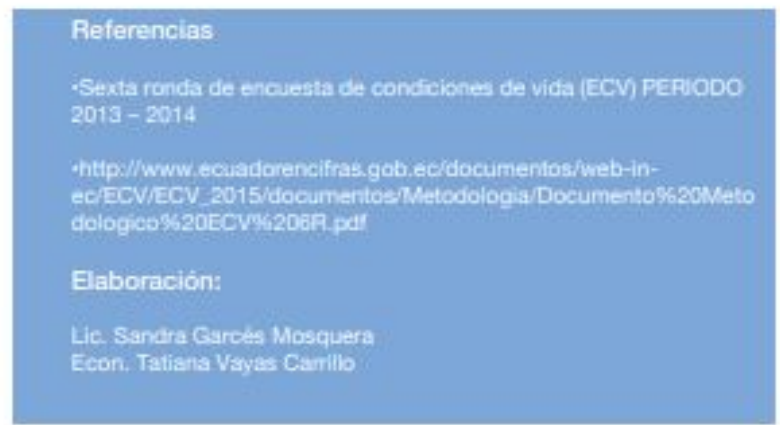

